\title{
Enfatemática del antiespañolismo en los textos de historia en países europeos $y$ americanos
}

\author{
Dr. Jesús Troncoso García
}

Profesor de Lengua y Literatura Españolas. Asesor Técnico-Lingüístico (MEC) de la Embajada de España en Italia. Miembro del Grupo de Investigación en Estructura,

Historia y Contenidos de la Comunicación. Universidad de Sevilla

\section{RESUMEN}

El autor analiza, a través de sus experiencias docentes y usando la teoría enfatemática, la pervivencia de un anacrónico antiespañolismo en numerosos textos históricos de países extranjeros. En especial, este estudio se centra en la consideración del libro de texto como un vehículo clave de comunicación cultural y, también, como un factor esencial para la formación de los alumnos como futuros ciudadanos de una Europa y América, en las que España, histórica y culturalmente, influyó durante siglos aportando su respetable civilización y cultura.

\section{ABSTRACT}

The autor analyses trough his educational experiences and using the enfathematic theory, the pervivencia of an anachronic antiespañolismo in numerous historical texts of foreign countries. Especially, this study is centered in the consideration of the text books like a key vehicle of cultural communication, and also as an essential factor for the formation of the students like citizens futures of an Europe and America, in those that Spain, historical and culturally, it influenced during centuries contributing its repectable civilization and culture.

Palabras claves: Teoría enfatemática/Enfatemas/Comunicación negativista/Urdimbre enfatemática/Desarrollo global/Anacronismo y Animadversión/Desinformación/Antiespañolismo.

Key Words: Enfathematic theory/Enfathemes/Enfathematic warp/Global development/Anachronism and antagonism/Disinformation/Antiespañolism.

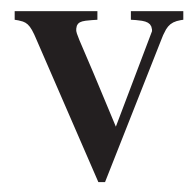

ivimos momentos de cambios globales apresurados que afectan indudablemente al interés de reconstrucción europeísta y también a la nueva imagen de lo hispánico en la coyuntura cultural panamericana. Mis años de trabajo en diversos centros educativos y culturales en Francia (1978-1981), Sudamérica (1983-84) y, actualmente, en la zona grecoitálica, me han hecho ver la dureza de muchos contenidos sobre historia de España en el contexto multiplicador y altamente persuasivo de muchos libros de texto, ilustraciones, obras gráficas y pictóricas. Se constata el hecho de la pervivencia de una enfatemática de comunicación negativista en textos didácticos referentes al antiespañolismo histórico en países europeos y americanos. 
Como paradigma generalizador y usando sólo como fuente libros en vigor actualmente en el ámbito educativo italiano, los fragmentos y textos extraídos de los manuales citados en el apartado de bibliografía, traducidos por mí al castellano para este artículo, son sólo una muestra de la especial, tópica y reiterada incidencia que se viene dando en numerosos textos didácticos comunitarios (Inglaterra, Francia, Alemania, Bélgica, Holanda...) sobre determinados aspectos negativos de nuestra historia, como también se aprecia desde antiguo, hasta con más acritud, en algunos libros de historia de países americanos.

Si bien existe una base de rigor científico evidente en cuanto a la objetividad y fijación textual de muchos de los hechos históricos descritos; también es cierto, ateniéndonos a los nuevas teorías de la comunicación, que existe cierta desinformación o manipulación de tales hechos, especialmente en aquellos relacionados con La Conquista de América. Lo que constituye, por tanto, desde la premisa fundamental de la que debemos partir en este estudio, considerando al libro de texto como un vehículo clave de comunicación cultural y, también, como un factor esencial para la formación de los alumnos como futuros ciudadanos de una Europa y América, en las que España, histórica y culturalmente, influyó durante siglos aportando su magnífica civilización y cultura.

La comunicación escrita y, con una mayor incidencia social, aquella de carácter educativo, sirve entre otras cosas para orientar las conductas de las personas y para mejorar su calidad de vida; es decir, para proporcionar los conocimientos necesarios, de manera que los alumnos puedan formarse un juicio propio y veraz de los acontecimientos históricos. Además, los excelentes libros de texto citados, perfeccionados también en su metodología y en su apoyo audiovisual, constituyen instrumentos principales para el actual cambio democratizador cosmopolita, toda vez que aportan nuevas ideas y suscitan inquietudes sociales, al tiempo que promueven el desarrollo global de los nuevos ciudadanos, al incidir fundamentalmente en la conformación de su personalidad y cultura.

No debemos seguir permitiendo la imagen deplorable que se da de España en algunos libros de textos, quizás como secuelas anacrónicas de muchos años de animadversión política y una evidente falta de respeto a nuestra historia. Es algo que hoy debería estar totalmente superado y que no refleja en absoluto la creciente admiración que en todos los sectores de las sociedades europeas y americanas se tiene por España, como un ejemplo a seguir de democracia armónica, moderna y positiva. Por tanto, aprovecho para exigir que desde las instancias que procedan deberían denunciarse estos enfoques históricos y bibliográficos en los foros internacionales relacionados con lo didáctico/educativo e, incluso, de forma juiciosa, incidir sobre editoriales, docentes, periodistas y escritores para convencerles de una nueva actitud, si se quiere crítica, pero también equilibrada y justa hacia nuestro pasado histórico. Se deberían alcanzar entre los países de la UE y de toda América, acuerdos mutuos para que se enfoquen sin acritud los referentes histó- 
ricos más polémicos que, si bien en gran parte son verídicos y debemos aceptarlos objetivamente en su dimensión y contexto histórico, también los jóvenes estudiantes deben conocer de nuestra común historia, en definitiva, un pasado más constructivo y un horizonte esperanzador.

Es una pena que en estos países, donde también existen numerosos hispanófilos e hispanistas de prestigio, los acontecimientos que se exageran de la Historia española no hayan sido a estas alturas reconducidos y enfocados de forma equilibrada y críticamente valorados en su rigor y justicia, y sólo se insista, deplorable y morbosamente, en los aspectos más negativos, potenciándose además lo escrito con grabados y dibujos alusivos a los acontecimientos y épocas referidas que subrayan aspectos de gran crueldad, con el denominador común de lo español como marchamo negativo.

En las significaciones negativas de los textos analizados se cae con gran facilidad en una desinformación que, lejos de una crítica constructiva, tiene todo el cariz de una "desinformación" como "información intencionadamente manipulada al servicio de ciertos fines"(Dic. Real Academia Española de la Lengua), abundándose en la utilización política que a veces se realizó de la "desinformación". A la cual, suponemos, no habría que llegarse en este caso. Comunicólogos de prestigio la han definido como el hecho informativo que se genera de un incumplimiento de las normas profesionales por parte de un autor o emisor que, como consecuencia produce un producto informativo incorrecto dirigido a receptores que, en este caso, serían los alumnos de Historia y Civilización de niveles medios y universitarios. Se hace así especial hincapié en los fragmentos más comprometidos de cronistas, escritores e historiadores españoles de la época descubridora como De Las Casas, Juan Ginés de Sepúlveda, Tomás de Ortiz, Gonzalo Fernández de Oviedo y Valdés, Montesinos, etc.

Para facilitar la urdimbre enfatemática, que a modo de recapitulación ofrezco como conclusión (Anexo I), se reproducen asimismo numerosos grabados que insisten en la crueldad y maldad de los españoles. Estos documentos gráficos suelen ilustrar algunos de los fragmentos de textos citados. En muchos casos las leyendas marginales que suelen acompañarlos evidencias incongruencias e inexactitudes con lo representado (Saco de Roma, Quema de brujas, etc.), por no coincidir icónicamente con los espacios sugeridos. Pues, posiblemente, muchos de tales dibujos, realizados con posterioridad a los hechos que ilustran, fueron realizados como encargos malintencionados (Leyenda Negra) y otros pueden proceder de épocas relativamente recientes como el siglo XIX, donde, debido posiblemente al auge del historicismo y a la misma independencia de nuestros territorios americanos y asiáticos, proliferó todo este tipo de manipulación propagandística.

En los ejercicios de Historia que aparecen al final de los temas, y también en algunos glosarios de los manuales citados, se continúa con una línea de 
profundización en los aspectos negativos más recalcitrantes, en algunos casos, condicionantes de respuestas demagógicas que favorecen un absurdo y anacrónico antiespañolismo en el alumnado (p.e. 7. 406, etc.)

Superados ya hoy los años de gobiernos totalitarios en Europa y en gran parte de Hispanoamérica, que utilizaron en demasía los fenómenos comunicativos de la persuasión y manipulación en su propio interés propagandístico, podemos considerar la intencionalidad de los enfoques reflejados en este estudio como una visión anticuada, deformante de los hechos y tendente descaradamente a un pronunciamento de mensajes carentes de principios, al desconectarse el propio mensaje de la visión reparadora que el paso de los siglos impregna en todos esos posibles hechos reprobables, imputados unilateralmente a los españoles. Porque, si la persuasión en ellos inmanente se apoya en juicios construidos en torno a un fundamento, por muy clarividente que éste sea, el análisis diacrónico y enfatematizador de la propia dinámica histórica, resultaría acre e hiperdevaluado a efectos de persuasión. Pues ésta, a través de las imágenes que configuran las fundamentales retículas poética y plástica de mi visión enfatemática globalizadora, no debe aislarse en aras de una manipulación por mucha inercia negativista que conlleven los actos comunicativos infrascritos; pues considero que, como principal premisa de un futuro alentador en el campo educativo e investigador, el fenómeno de persuasión, con todos mis respetos a la libertad de cátedra y a la libre expresión, no puede estudiarse sólo como la influencia que un autor ejerce sobre un destinatario, sino que, en los albores de este tercer milenio, los realizadores de los potentes medios y las mismas sociedades implicadas deben confrontarse, crítica y verazmente, en un consenso mutuo de compartidas realidades históricas.

\section{SELECCIÓN DE IDEAS Y SUPUESTOS HECHOS HISTÓRICOS recaba- dos de la selección de textos citados en la bibliografía final.}

\section{Observación:}

Los siguientes fragmentos de textos aparecen introducidos por siglas que temáticamente los engloban en una determinada problemática. La fijación textual aparece entre paréntesis según las claves recogidas a continuación:

*Valoraciones estimativas: Positiva (+)

Negativa (-) 
*SIGLAS:

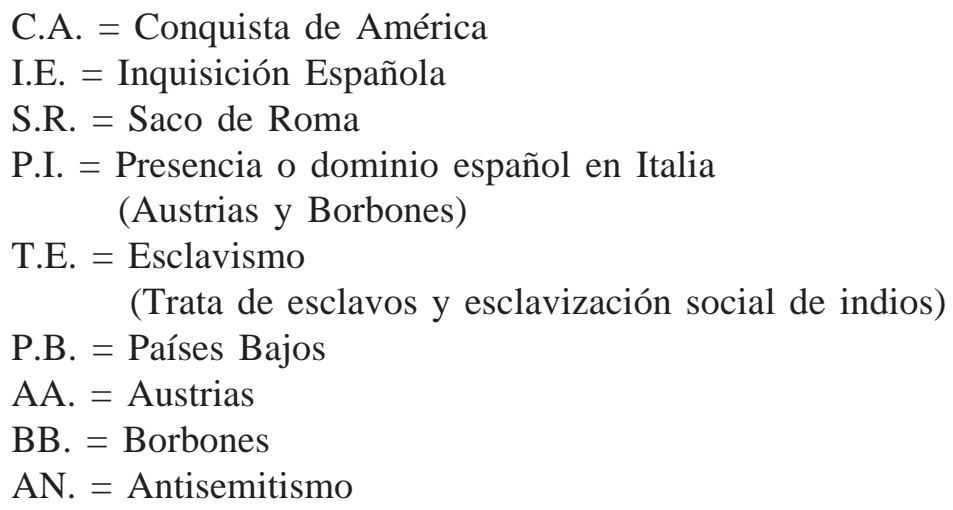

*Citas: p.e., la (3.456), indica el libro reseñado con el n³3, pág. 456

\section{Fragmentos y textos escogidos de los manuales citados:}

1. -C.A.) Envidias y calumnias hacia Colón por parte de los españoles

a. (9. 146)

1. -C.A.) Abandono a Colón por la Corte española tras su regreso a España (9.146)

2. -C.A.) Ridiculización y avidez: "apetitos de España desencadenados por el Descubrimiento"(9.146)

3. -C.A.) Acusación de rápido y fácil enriquecimiento a manos de "aventureros" españoles violentos y sin escrúpulos (9.150)

4. -C.A.) La utilización de la mentira como arma de guerra (caballos antropomorfos, naturaleza divina de los aventureros españoles...) (9.150)

5. -C.A.) Crueldad de los conquistadores españoles como sembradores de muerte y destrucción (9.150)(1.42)

6. -C.A.) Todo era como una guerra tras la loca alucinación del oro y el desencadenamiento de una ferocidad ilimitada que trasformó a los conquistadores en ladrones y asesinos sin virtud y sin honor (1.43)

7. -C.A.) Los españoles tomaban la decisión de matar, cerraban las salidas de los lugares donde los indios celebraban ritos y allí le acuchillaban y cortaban brazos y cabezas. La sangre de los indios -se dice- corría como si fuese agua (9.370)

8. -C.A.) Se preocupaban sobre todo de la búsqueda del oro y plata, recurriendo sin escrúpulos a la violencia y al asesinato (2.16)

9. -C.A.) Perros feroces adiestrados para la guerra: Donde no podían entrar los caballos por la aspereza del terreno los españoles utilizaban temibles perros. Algunos se hicieron famosos, como el llamado "Leoncillo", que tenía todo el cuerpo lleno de cicatrices que había recibido batiéndose con los indios (7.401) 
Los españoles utilizaban esta superioridad psicológica haciéndole creer a los indios que los encolerizados caballos participaban en la batalla por su propia voluntad. (7-401).

10. +C.A./T.E.) Bartolomé de Las Casas decidió hacerse fraile y dedicar su vida a la causa de los indios al ver las atrocidades de la dominación española en la región americana donde vivía con sus padres (7.407) (10.148)

11. -C.A.) Los primeros españoles que se establecieron en América obligaban a trabajar a los indios sin preocuparse siquiera de alimentarlos, por esto morían, por la desnutrición y la fatiga...(5.262)

12. -C.A.) Muchos nobles españoles y sus hijos menores se establecieron en América para enriquecerse ..., apoderándose con todos los medios que podían del oro disponible y destruyendo los grandes imperios de la América centromeridional (5.262)

13. -C.A.) La voz de De Las Casas no fue escuchada y las cosas no cambiaron en absoluto (10.148)

14. -C.A.) En 1531 el obispo Zumárraga se jactaba de haber destruído 500 templos aztecas y 20.000 ídolos. El mismo emperador Carlos V aconsejaba la reutilización de dichos materiales de derribo para la construcción de nuevas iglesias. En cuanto a la cristianización de los indios, éstos eran bautizados bajo amenaza de prisión y tortura y en muchos casos incluso se les condenaba a muerte (7.404)

15. -C.A/T.E.) La esclavitud: Los españoles no sólo matan y destruyen sino que también convierten en esclavos a los indígenas y les obligan a trabajar abusivamente en minas y plantaciones (9.150)

16. -C.A./T.E) La expediciones de Almagro y Pizarro fueron una sucesión de horrores, desastres, devastaciones, crueldades y gran exterminio de la población, reduciéndose a los supervivientes a la esclavitud (7.398) (10.148)

17. +C.A.) El rey de España ante tantas barbaridades de los primeros conquistadores promulgó una ley para declarar libre la población indígena esclavizada (9.150)

18. +C.A.) Gracias al Decubrimiento de América se pudo transformar y enriquecer Europa e Italia en numerosos aspectos económicos, políticos y sociales (9.150-151-152)

19. -C.A.) Los españoles destruyeron los reinos e imperios que existían antes de su llegada al continente americano (9.157)

20. -C.A./ P.I.) Los españoles utilizaron siempre a los papas, tanto económica como políticamente (9.157) (9.192)

21. -AA.) Con Felipe II, paradójicamente, España, la mayor potencia colonial europea era en sí misma una colonia (7.200) 
22. -AA./ I.E.) Represión religiosa de Felipe II: Su proyecto religioso y político fue perseguido con las violentas armas de la persecución y de la guerra santa: la Inquisición española está constantemente empeñada en la represión de los focos de herejía, en la dispersión de la comunidad de conversos (judíos convertidos a la fe católica) y moriscos (musulmanes convertidos). Autos de fe solemnes que el mismo rey presidía...(8.2.570)

23. -I.E./AA.) El Consejo Supremo de la Inquisición, conocido como "Suprema", que dirigía los otros 21 tribunales existentes en España se reunía en el Palacio Real de Madrid..., el mismo Felipe II presidió personalmente los autos de fe donde se dieron sentencias rituales a grupos notables de herejes en Valladolid, Toledo, Barcelona, Lisboa, etc. Entre 1550 y 1770, el Tribunal del Santo Oficio trató aproximadamente 150.000 casos de heterodoxos protestantes, moriscos o hebreos conversos, siendo motivo incluso de encausamiento la bigamia, la homosexualidad o la fornicación (8.2.571)

24. -I.E./A. -A/AN.) Desprecio y sospechas de los españoles hacia los judíos conversos y moriscos: los judíos conversos o "marranos", como también eran llamados, fueron pronto controlados religiosamente por el tribunal de la Inquisición, reconstituido en 1478 por el Papa Sixto IV. En Sevilla en 1481 ardía el primer fuego inquisitorial envolviendo importantes exponentes de ricas familias burguesas de conversos (1.70)

25. -AA.) Aunque la Inquisición fue confiada a los dominicos, también fue un órgano del Estado y por tanto fue utilizado por los monarcas españoles durante tres siglos como importante instrumento de poder, adaptándose según las circunstancias a las necesidades de la Corona (1.70)

26. -AN) A lo largo de la Edad Media, España fue el país cristiano donde se fue gestando el más áspero antisemitismo hacia los judíos, su creciente riqueza contribuyó a que fueran envidiados y odiados. Sobre todo fue en el S. XIV cuando comenzaron a ser discriminados por la autoridad civil y eclesiástica y a sufrir, tras violencias e intimidaciones, la posterior masacre, célebre fue aquella de 1391. Durante el S. XV en bastantes regiones españolas era habitual la caza del judío, hasta que en 1492 los Reyes Católicos decretaron la expulsión de aquellos que en el plazo de cuatro meses no se hubieran convertidos...(2.46)

27. -AN) La suerte que tocó a los hebreos pasó también a los moriscos que en el S. XVI conocieron persecuciones, conversiones forzadas, las pesquisas de la Inquisición y finalmente la expulsión en masa (2.46)

28. -P.B.) Los motivos de roce de todo tipo entre España y Los Países Bajos eran numerosos(7.549)

29. -P.B.) La rigidez de la política de Felipe II precipitó el levantamiento de las masas populares desesperadas por años de desempleo, encarecimiento de precios, hambre e instigaciones de los calvinistas, entregándose al saqueo y la 
masacre. Para poner orden es enviado el Duque de Alba que logra severamente consolidar a la Corona, eliminando a los herejes...(7.550)

30. -P.B.) El Duque de Alba no sólo había perseguido a los herejes, devastando sus bienes y difundiendo el terror al tiempo que subía los impuestos para poder pagar a los tercios, sino que cuando tardaban las pagas a la tropa, la soldadesca se dedicaba a los más variados estropicios bajo el terror de la población (2.148) (2.149)

31. -P.I.) España fue culpable con Francia de la división de "Italia" (9.162)

32. -P.I.) Carlos V, frío y calculador, estaba al frente de un Imperio sin porvenir y que simplemente conformaba una realidad político-geográfica sin ninguna unidad (9.376)

33. -S.R.) Los españoles aparecen en muchos textos como responsables directos del Saco de Roma que supuso 4.000 muertos, prisioneros, rescates enormes, humillaciones de los dignatarios de la Iglesia, torturas, etc. (9.380)

34. -S.R.) Impasibidad del emperador ante los atropellos del Saco de Roma:

En su sede de Burgos, en Castilla, el emperador no hacía nada para frenar el ataque de los mercenarios(7.535)

35. -P.I.) vid. Alusiones en el "Discorso al popolo napoletano"(7.717-718)

36. -P.I.) S. XVI - XVII. Dominio de España en Italia: realizaron una política de rapiña y explotación abusiva de todas las fuentes de riqueza italianas (9.188).

37. -P.I.) El "fiscalismo" español en Italia supuso la imposición de tributos y tasas de todo tipo que además no aportaban ningún beneficio a la población, sino que sólo servían para pagar las muchas guerras que España tenía entonces (9.188)

38. -P.I.) La opresión política y la explotación económica española en Italia duró más de un siglo y medio con gran prepotencia y daño a la gente más humilde que en numerosas ocasiones se rebeló (9.188) (9.199)

39. -C.A./AA.) Emblemático fue el caso de España que confió su economía a la ingente remesa de metales preciosos del Nuevo Mundo, sosteniendo con el oro y la plata llegados del Nuevo Mundo las ambiciones de la Corona que había consentido a la clase dirigente ibérica el desprecio por la actividad productiva (6.92)

40. -P.I.) La política española de desorden, miseria, envilecimiento y desolación moral, agravada por las alzas de precios y las epidemias de peste, causó la disminución de la población en un millón y medio de habitantes (9.188)

41. -P.I.) Extorsiones fiscales en el Reino de Nápoles: Los pueblos y campos estaban exterminados a causa de los grandes tributos. Infructíferamente acudió en múltiples ocasiones la población a los virreyes, incluso una comisión de religiosos napolitanos se trasladó a la Corte en Madrid, impidiéndosele hablar con el rey (9.388) 
42. +P.I.) Al referirse al arte y literatura universal del siglo XVII se destaca la importante labor de escritores españoles como Calderón, Lope de Vega y Cervantes con su obra inmortal Don Quijote. También se refieren a Velázquez como gran pintor (9.196)

43. -I.E.) Cuando se habla de Inquisición, a pesar de ser ésta un fenómeno europeo lo suelen radicar especialmente en España: "La Inquisición en España utilizaba hábilmente la tortura. Incluso Cervantes denunció la utilización por ella de los mismos métodos de los tribunales ordinarios. España-se dice- usó el hierro y el fuego para resolver las cuestiones religiosas y las opiniones diferentes a la oficialidad (9.213)

44. -I.E.) Se destacan los métodos usados por la I.E. como de gran vileza, incluso los arrepentidos son quemados y sus bienes confiscados. Los que se declaran culpables sufren cadena perpetua en cárceles subterráneas en señal de misericordia cristiana, se les tortura con una gran variedad de instrumentos. Los que, difícilmente, demuestran su inocencia, deben pagar multa, para que "no se pueda decir que actuaron sin razón", e incluso así, la indignidad de todo detenido aunque no hubiese sido encausado ni condenado se trasladaba a toda la familia como un grave tormento social (9.388) (1.70)

45. -I.E./A.A.) En enero de 1567 una proclama real imponía a los moriscos el abandono de su lengua, costumbres, prácticas religiosas y modo de vestir (8.2.573)

46. -C.A.) Los españoles, pretendiendo difundir el conocimiento de su verdadero Dios, destruyen impunemente los templos y estatuas de los vencidos convenciéndoles de cómo, hasta entonces, habían adorado a falsos ídolos (7.438)

47. -C.A./T.E.) Esclavos. Adaptaciones manipuladas de textos originales: los indios llevados en el primer viaje de Colón a España en 1495 aparecen como esclavos que en su gran parte mueren por el camino (9.366)

48. -C.A./T.E.) Esclavos: Los conquistadores saciaron su desenfrenada sed de oro, tierras y esclavos en el imperio de los Incas(6.90)

49. -T.E.) Portugal y España empezaron a tener una decisiva influencia sobre el Continente Negro..., abriendo a la creciente demanda de esclavos para utilizarlos como mano de obra en las plantaciones y minas americanas (6.274)

50. -C.A./T.E./BB.) Borbones: Se resalta del "Asiento de Negros", el régimen de monopolio dado por Su Majestad Católica Felipe V de España a la Cía. De Guinea para la introducción de los esclavos negros en las Indias Occidentales de América, obligándose a introducir durante diez años a partir de 1702 la cantidad de 40000 negros de los dos sexos (9.422). Dicho texto se acompaña de grabados de la época donde aparecen los duros e inhumanos trabajos de los indígenas y las caravanas de negros usados para transportar a cuestas grandes pesos (9.423) 
51. -C.A./T.E.) Esclavitud: Se asocia en exceso lo español con la trata de esclavos creándose un contexto implicatorio, en el 9.444 al hablar de Las Casas, como obispo de una ciudad de Méjico, se resalta como en su "B.R. de la Destrucción de las Indias" se denuncia el exterminio de los indios de Haití que fueron reducidos de un millón a sólo 60.000 supervivientes, sugiriendo el autor para reponer tales desastres demográficos que cada español pudiese importar doce negros africanos, aunque tales negros no fuesen considerados -al igual que los indios aborígenes- miembros de la comunidad cristiana, pues los negros para los españoles como tales esclavos eran considerados enemigos capturados en acción de guerra (9.444)(5.262)(5.269)

52. -C.A./T.E.) Para contabilizar todos los negros llevados por la fuerza a América hay que añadir, además, el número de los que murieron masacrados en las numerosas capturas o "cacerías" africanas, y también la de aquellos muertos en las travesías de las naves negreras (9.444)

53. -C.A./T.E.) El fraile Tomás Ortiz defendía que todos los indios deberían reducirse a la esclavitud, basando su tesis en numerosas cualidades negativas que éstos poseían: canibalismo, desnudez, demencia, estupidez, indolencia, instintos criminales, drogadicción, promiscuidad sexual, brujería, etc. $(7.404)(1.42)$

54. -C.A.) J.G.de Sepúlveda: La conquista de los españole era sin duda un caso de guerra justa, porque aquellos indios depravados y salvajes no podían tener ningún derecho en el enfrentamiento con un pueblo cristiano..., el mismo Rey de España parecía haberles dado la razón (1.43), visto que el mismo había instituido desde 1521 el sistema de las encomiendas, en base al cual poblados enteros aztecas pasaban a depender de un conquistador (1.43)

55. -C.A.) Genocidio y deportación*: Las abundantes valoraciones como la anterior ofrecían una justificación para el saqueo y la guerra de rapiña y del genocidio que los conquistadores pusieron pronto en práctica. Pues la destrucción de los indígenas entraba incluso dentro de un plan divino, pues, como también decía el fraile Ortiz, los indios que eran "Obscenos como puercos"practicaban además ritos monstruosos en honor del diablo (7.404) (7.442) (2.16)

*Nota: Una posible muestra de las influencias de estos textos en los manuales en vigor se encuentra actualmente tanto en prensa como en algunos debates televisivos en los que también se aprecia con frecuencia un velado antiespañolismo. Valga como muestra el epílogo/conclusión de un ensayo a cuatro columnas en el suplemento cultural del diario italiano "La República" del 29-01-99, pág. 42, donde en el contexto del genocidio nazi, el autor Gabriele Franzato, se refiere finalmente al holocausto nazi diciendo: “...el genocidio no es un producto sólo del odio, pues como dice T. Todorov en su obra "La 
Conquista de América” (edit.Einaudi): “...los españole no sólo comprendían, sino que incluso admiraban a los aztecas, y sin embargo lo aniquilaron, ¿Por qué?, -porque posiblemente todo aconteció como si los españoles experimentaran un placer especial en la crueldad, en el ejercicio del poder sobre los demás, en la autoconstatación de poder matar."

56. -C.A.) Genocidio: ...el genocidio de los indios permanece entre los españoles como una mancha imposible de eliminar. Todos los enemigos políticos de los españoles se apresuraron desde entonces a describirlos todavía más crueles de lo que realmente habían sido (1.43)

57. -CA) Genocidio: ...la conquista en Perú se convirtió en un auténtico genocidio: Pizarro con 180 hombres y 37 caballos aniquiló al imperio Inca en dos años. Tal violencia hizo que el mismo emperador Carlos $\mathrm{V}$ ordenase que se detuviera el proceso conquistador (4.35)

58. +C.A.) Los españoles a lo largo de la Conquisa fueron en general menos racistas que los anglosajones y holandeses (en los territorios por ellos conquistados)(1.43)

59. -C.A.) Avidez por el oro: Los españoles se apropiaron de todo los objetos preciosos reduciéndolo a oro $(9.370)$

60. -C.A.) Los españoles eliminaron a los emperadores de los dos grandes imperios: el azteca Montezuma , que fue ajusticiado, y también, el inca Atahualpa, ajusticiado tras haberse cobrado una gigantesca cantidad de oro por su liberación (7.399)

61. -C.A.) La expedición de Almagro y Pizarro fue una sucesión de horrores, la población además fue exterminada o reducida a la esclavitud (7.398)(4.32)

62. -C.A.) La conquista se mantuvo gracias a los medios utilizados de masacre y destrucción, mediante, entre otras maldades, del denominado "choc micróbico", auténtico trauma biológico causado por enfermedades desconocidas en el ecosistema indígena (resfriado, sarampión, sífilis, etc.) y la introducción del consumo del alcohol (7.400)(7.407)(5.263)

63. -C.A.) Destrucción de la cultura indígena: Para los conquistadores los indígenas sólo eran energía de consumo para utilizarse en los insostenibles trabajos agrícolas (7.403)

64. -C.A.) Duros enfrentamientos entre los mismos españoles (p.e. Cortés versus Narváez)(8.1.276)

65. -C.A./T.E.) Los españoles llevaron a América el régimen feudal y opresivo de las "encomiendas", con prestación de trabajo ilimitada, así murieron millones de indios en las minas de plata bolivianas y otros tantos en las arenas auríferas de los ríos. Poblados enteros indígenas eran repartidos entre los encomenderos al igual que poco antes lo hacían con el oro y los esclavos (7.402-403) (2.176) 
66. -C.A.) En 1519 apareció Cortés en las costas mejicanas lo que fue interpretado como el enviado divino que esperaban los aztecas por esas fechas. El mismo rey se sometió a Cortés, pero el pueblo azteca desesperado de la violencia de los soldados españoles se levantaron y mataron a su propio rey (6.281) (8.2.258)

67. -C.A.) La economía colonial consistía en una explotación de rapiña, que sólo sustraía recursos sin crear ninguna inversión (7.403)

68. -C.A.) Desprecio al indio: el cronista de Indias Gonzalo Fernández de Oviedo y Valdés, autor en 1526 de "Sumario de la natural y general historia de la Indias" se caracteriza por fuertes prejuicios morales y gran desprecio hacia los indios que se concreta en el macabro augurio de un exterminio total (7.438)

69. -C.A.) Ginés de Sepúlveda, escribe: Los indios no son por tanto hombres sino una raza extraviada que debe ser empujada a la fuerza hacia las reglas de la vida cristiana...Sus grandes obras de civilización no son prueba de una mayor pericia humana, desde el momento que vemos también a ciertos animales como las abejas y arañas construir obras que ninguna actividad humana sabría imitar(1.43)

70. + C.A.) Dignidad y derecho del indio: Bartolomé de las Casas, antes que con sus libros, había defendido el derecho de los indios a ser respetados como hombres con su propia actividad diplomática, dirigida al Rey de España, demostrando además poseer una dote especial en aquel tiempo: "la capacidad de superar el abismo cultural hacia los indios, buscando comprender desde dentro sus propias costumbres, sus códigos sociales y sus creen$\operatorname{cias}(1.43)$

71. -C.A.) Alusión de las depravaciones sexuales de los indios, destacadas en las crónicas de G. F. de Oviedo (7.438)

72. +C.A.) Finalmente el esfuerzo lascasiano parecía haber tenido éxito pues en 1537, el Papa declaró herética la tesis que declaraba a los indios como incapaces de entender la palabra de Dios. En 1542, Carlos V abolió las encomiendas. En 1550 el mismo rey de España prohibió la publicación del libro de Sepúlveda (1.43)

73. -C.A.) Escribe el español G. F. de Oviedo: “... Los indios tienen el cráneo cuatro veces más grueso que los cristianos, por eso cuando con ellos se hace la guerra hay que tener cuidado de no darle con la espada en la cabeza, pues se han visto romperse muchas espadas por la causa citada" (7.439)

74. -C.A.) Se publican textos de Las Casas que inciden sobre la crueldad de los españoles (7.443- $444-446$ - 451)

75. +C.A./T.E.) Las revelaciones del dominico Antonio de Montesinos sobre la feroz explotación de los indios, provocó el primer intento de legislación colonial, aquélla conocida como "Leyes de Burgos", que prohibían a las colonias ser consideradas como reservas de esclavos, limitándose además a 
legalizar la forma de organización del trabajo que los primeros colonos habían instaurado (3.10)

76. -Moriscos) En España el espíritu de cruzada, revitalizado por la lucha contra el turco, se trasladó a una feroz persecución de los moriscos (musulmanes bautizados en España), acusados de esconderse detrás de una apariencia cristiana y de representar una "quinta columna" turca en el seno de la sociedad española, fueron siempre perseguidos y marginados y, en 1609, fueron expulsados los supervivientes. Otros muchos millares habían sido eliminados (7.548)

77. -C.A.) Ni las denuncias de dominicos ni la legislación dada al respecto pudo impedir el genocidio de los indios, reducidos además a la esclavitud (6.421) (10.148)

78. -C.A.) La Conquista no fue conducida directamente por la monarquía española, sino por aventureros llamados "conquistadores" a la búsqueda de metales preciosos (10.145-146) (8.1.275)

79. +C.A.) No siempre el encuentro entre colonos o misioneros y los indígenas tuvo las consecuencias traumáticas de las encomiendas. En las reducciones jesuíticas, la obra evangélica, la educación y promoción humana se desarrollo en una atmósfera de pacífica convivencia y colaboración, al cobijo de la violencia y la explotación (8.1.278)

80. -S.R.) Las tropas españolas se lanzaron al asalto de Roma y se entregaron con furor durante días a saquear la ciudad, obteniendo un ingente botín. Nada fue respetado, ni hombres, ni cosas, ni símbolos sacros ni profanos (8.1.353- 354)

81. -C.A.) Durante el asalto a Tenochtitlán los acueductos fueron cortados y los edificios fueron destruidos uno a uno con meticulosa ferocidad. Cuando todo terminó, Tenochtitlán era una ciudad muerta, una ciudad de muertos (1.43)

ILUSTRACIONES (Se trata de grabados y dibujos en los libros referidos con textos alusivos en leyendas marginales)

-P.I.) Velázquez. Las Hilanderas (fragmento): el trabajo manual se pone como ejemplo de las míseras condiciones de vida del pueblo (9.189)

-I.E.) Quema de herejes en la plaza mayor de Valladolid en 1559 (9.213)

-C.A.)Cortés en Méjico. En las leyendas se hace hincapié en la canallesca y temeraria aventura de los conquistadores, hombre sin escrupulos . Los españoles vencieron por su superioridad de las armas de fuego (9.371)

+ C.A.)Primer encuentro entre Cortés y Montezuma: los indígenas acogen a los españoles recienllegados con regalos(7.401)

-C.A.)Ataque con naves, caballos y cañones a una fortificación costera indígena: se resalta aquí la superioridad bélica de los españoles (9.401)

-C.A.)Canibalismo de los indígenas (7.405) 
-C.A.) Corte de la Mano: castigo o suplicio impuesto por los españoles a los indígenas rebeldes o fugitivos. Se aprecia a éstos cortando las manos de varios indios (7.405)

-P.B.) Ejecuciones en masa de rebeldes holandeses: se muestra la dureza de la represión española a través de ahorcamientos sistemáticos y degüello de la población inerme, incluso mujeres y niños.(7.550)

-F) La matanza de la noche de S. Bartolomé: en el texto adjunto se asocia la masacre con la opresión religiosa que se encarnaba en la figura de Felipe II y en España (7. 560)

-C.A.) Prisión de Atahualpa: grabado del códice peruano de Guamán (6. 91)

-C.A.) Traslado de artillería (dibujo con original desaparecido de Tlaxcala): los indios transportan sobre sus hombros a los españoles y piezas de artillería desde la costa al altiplano mejicano (6.91)

-C.A.) Indios trabajando en una mina aurífera(grabado de "Americae" de Francfurt.1590): ilustra las duras condiciones de trabajo en una peligrosa mina de oro excavada en una colina(6.92)

-I.E.) Quema de judíos en la hoguera (grabado español S.XVI): aparece en un contexto en el que si bien no se alude directamente a los españoles, se les implica con este grabado de autoría española en el antisemitismo y antisatanismo, al que se alude en el texto de la misma página(6.146)

-I.E.) Ejecución pública de brujas y cómplices quemados en la hoguera (grabado español del S.XVII): este grabado que representa una extraña y anónima ciudad portuaria española, aparece además ilustrando todo un texto referente a la brujería en Europa (6.363)

-C.A./T.E.) Marca de esclavos y trabajos de aztecas en campos y minas (pintura contemporánea): Los españoles contratan y controlan el trabajo obligando a los indios a trabajos pesados en condiciones inhumanas. Los españoles marcan despiadadamente a los esclavos importados (10.149)

-C.A./T.E.) Esclavos negros en las minas (grabado): Entre 1500 y 1800 fueron importados a América treinta millones de esclavos negros de África, una vez Carlos V prohibió la esclavitud de los indios en 1542 (10.149). Otros grabados sobre trabajos duros (5.265) (5.266)

-C.A./T.E.) Esclavos negros como cortadores de caña de azúcar. Siglo XVIII (grabado popular de la época): Aunque no se cita aparece en un contexto español (6.94)

-C.A.) Siete dibujos anónimos de la época de la conquista azteca(S.XVI): $(8.1,275-277)$

-C.A.)Combate entre indios y conquistadores (dibujo del S.XVI): destruyen en brevísimo tiempo un imperio potente como el de los aztecas..., fue el fin de una civilización antigua y refinada. Aparecen indios ahorcados y descuartizados, tras la acción de ataques de perros y españoles a caballo (2.17) 
-C.A.) Destrucción de un poblado indígena a mano de los españoles: a las rebeliones populares indígenas, los españoles contestaron destruyendo poblados y masacrando a sus habitantes (5.83)

\section{Bibliografía}

(manuales que han servido de referencia, equivalentes a nuestros niveles actuales de Educación Secundaria Obligatoria, Bachillerato y Primer ciclo universitario):

1.- Guarracino, Scipione. Storia dell’Età Moderna. E.E.B. Mondadori.

2.- $\quad$ Prandi, Alfonso. Corso di storia dell' età moderna per i Licei e gli Istituti Magistrali.

3.- Villari, Rosario. Storia Moderna. Edit. Laterza.

4.- $\quad$ Pellitero, Mercedes; Jaume, Bárbara y Blanco, Carmen. Español, Lengua y. Cultura Edit, Zanichelli.

5.- Neri, Ricardo. Nuovo progetto di storia. Edit. La Nuova Italia-2

6.- Gentile, Ronga y Salassa. Nuovi Percorsi nella Storia.1. Edit. La Scuola, Brescia, 1997(3 tomos)

7.- Giardina, Andrea; Sabbatucci, Giovanni y Vidotto, Vittorio. Profili storici del 1200 al 1650. Edit. Laterza. $1^{a}$ edic,1997. Roma-Bari.

8.- Manzoni, Marco y Occhipinti, Francesca. I territori della storia. Einaudi Scuola. Milano, 1998 ( $1^{\text {a }}$ edic.)

I Tomo: Dal Medioevo all'età moderna (secoli XIV-XVI)

II Tomo: Un' epoca di grandi conflitti (secoli XVI- XVII)

9.- $\quad$ Brancati, Antonio. Fare Storia.2. Edit. La Nuova Italia. Firenze, 1988 (4 ${ }^{\mathrm{a}}$ edic.)

10.- De Rosa, Gabriele y Cestaro, Antonio. Mito, storia, civiltà. Edit. Minerva Italica. Milano-Roma, 1984

Breve explicación del término y concepto "enfatema". introducción sobre la teoría enfatemática.

La necesidad de encontrar una unidad analítica, contrastiva y de interrelación para relacionar y estudiar a fondo los significados de un periodo histórico desde una perspectiva plural de lenguajes verbales e icónicos, me condujo al diseño de los enfatemas en mi tesis doctoral interfacultativa (Filología y Bellas Artes) titulada "Interrelación de lo plástico y poético en la obra de Amalio García del Moral". Tales enfatemas, actúan como unidades analíticas de insistencia significativa en campos de interrelación semántica, con la finalidad de un mejor análisis del hecho o fenómeno creativo en su significación profunda y proyección hacia otros campos del saber, de la cultura y el arte. 
Los enfatemas, como unidades funcionales básicas de comunicación para el análisis de visión general o amplio espectro, posee las siguientes características:

a) Conducen al análisis total o global del conjunto creativo de un autor, escuela, periodo histórico, movimiento cultural o artístico.

b) Sirven para sintetizar o reflejar los temas de mayor énfasis, reiteración $e$ insistencia de la obra/s de un autor/autores en uno o en varios lenguajes concomitantes y coetáneos o no coétaneos, a modo de factor común semántico, exista o no pluralismo en la dicción de la obra artística, sea literaria o plástica, en su amplia gama de géneros estilos y modalidades.

c) Relacionan los significados de obras unilateralmente creativas con las del contexto artístico o socio-histórico, con el que se encuentran, por su fondo y forma, emparentadas.

d) Se interrelacionan conformando una urdimbre de significación global en las correspondientes redes creativas que a su vez están integradas por las retículas que como amplios conjuntos monotemáticos engloban las imágenes de los diferentes lenguajes verbales/no verbales. De ahí las retículas poética, plástica y cultural ( histórico-social o contextual). Como ejemplo del funcionamento enfatemático que, finalmente será aplicado en el presente estudio, desarrollo una de los miles de enfatemas encontrados en la obra amaliana objeto de mi inédita tesis referida, concretamente el enfatema denominado EL PAN, extraído de la red creativa titulada "El Pensamiento Amaliano":

\section{$\langle\boldsymbol{E}($ Enfatema $)\rangle$}

EL P A N

-R.PL. (Retícula Plástica).

Obras plásticas donde

se alude a la imagen "pan"

EL PAN ENCADENADO

-Imagen presente-
-R.P. (Retícula Poética)Textos donde aparece literariamente la imagen "pan"

t.1. "Por eso al hablar del pan/ del pueblo siempre me acuerdo/ y cuando al pan se consagra,/ se está consagrando al pueblo" PM.1-2/19 
EUCARISTÍA

-Imagen simbólica-

EL CUENCO VACÍO

-Imagen por ausencia-

APOSTOLADO PROLETARIO

-Imagen por extensión-

EL MUNDO DE ESPERANZA

-Imagen por extensión y analogías-

LA ANDALUCÍA NEGRA

-Imagen por extensión-

$\wedge$ t.2. (...se va nutriendo

hambrienta mi pintural con un oscuro pan, carne del pueblo,) LMF. 1-2/19

t.3. "iQue respeto me causan estos hombres cuando comulgo con su pan fraterno! LMF. 15-16/19

t.4 "...Mi pincel es la mano que modelal estas hogazas de bocado tierno. "LMF. 5-6/37

1.5. "Amarillo:/ Cuando soñando pan granan las mieses/ y es fuego el Sol..." TL. 1-3/30

t.6. “...Una lágrima es acre levadural que esponjará este Pan con su fermento. LMF. $11-12 / 19$

\section{-R.CULT.-}

(Retícula Cultural)

-El pan como símbolo del trabajo -Influencia del Realismo social en la literatura y el arte

-El Arte como compromiso

-Influencia del sentido bíblico y cristiano del pan

-Connotaciones antropológicas del pan en Andalucía(tipos culturales y artesanía: figuritas de pan en muchos pueblos andaluces) 
-Vibraciones cromáticas(aplicación

de la ley del contraste simultáneo)

Comentario: Como puede apreciarse en este ejemplo, en el caso de Amalio, los enfatemas surgen como una urdimbre sígnica connotativa de la interrelación de la retícula plástica, poética y cultural, como una macroexpresión artística implícita en el hecho social.

Se trata además, por su carácter literario y plástico, de una comunicación indirecta e interactiva, cuya verdadera interpretación sólo puede deducirse metatextualmente a través del concepto de los enfatemas. Todas las redes creativas, a su vez, generan el macrosistema de la obra total de Amalio. En ellas, los enfatemas dependen, sin jerarquización ideológica, de un enfatema central que suele coincidir con el título de la red creativa donde se integra: Giralda, Paisaje, Andalucía, Flamenco, Luz, Pensamiento, Espiritualidad, Muerte-Tiempo, Pintura, Poesía, etc.

En las redes creativas, los enfatemas que las integran participan por igual correlativamente de la esencia integradora de sus retículas básicas: la plástica y la poética.Incluso en las profundas antinomias de Amalio (pág.1053 de la tesis), ya desdobladas de por sí en la doble conjunción plástico-poética, la fuerte dialéctica producida por el choque conceptual de los enfatemas en tales binomios antitéticos, producen el contraste pero nunca la dispersión: vida/muerte, libertad/ opresión, justicia/injusticia, luces/sombras, Dios/tinieblas, trabajo/hambre...; como por ejemplo ocurre con la citada antinomia luces/sombras, donde lejos de destruirse los enfatemas en su propia "literalidad", conforman en Amalio todo un camino místico, a pesar de la lucha abierta del poeta con el lenguaje coloquial. En sus tactopinturas no figurativas y sus monólogos del silencio, la ausencia total o parcial de un determinado tema está compensada por la gran fuerza subjetiva que se desprende de sus obras, transmitiéndonos en su pura abstracción una gran sensación de movimiento, acción, turbación y espiritualidad, en ese caso también cabría la posibilidad de hablar de enfatemas abstractos. 


\section{Anexo I.}

Enfatemas presentes en los textos citados de los libros de Historia reseñados, como síntesis comunicativa
R.PL.>
$\mathbf{E}$
$<$ R.P.

<ESPAÑA. Dominación y crueldad>

-CORTE DE LA MANO -ESPAÑOLES-

10-12-16-20-21-41-47-49-56-

57-58-60-61-64-65-66-75

Explotación del indio/ Enriquecimiento/ Destrucción de culturas indígenas/ Esclavitud/ Alza de precios/ Epidemias/ Genocidio/ Deportación/ Eliminación de emperadores indios/ Enfrentamientos entre Ellos/ Régimen feudal de encomiendas

-COLÓN - 1-2-

Envidia/ Calumnia/ Abandono/ Ridiculización

-DESCUBRIMIENTO- 19

Avidez/ Enriquecimiento

-GUERRA- 5-10-55

-TRASLADO DE ARTILLERÍA ATAQUE CON NAVES, CABALLOS Y CAÑONES

-DESTRUCCIÓN DE UN POBLADO INDÍGENA A MANO DE LOS ESPAÑOLES
Armas: Mentira/ Caballos antropomorfos/ Naturaleza divina/ Perros feroces/ Superioridad psicológica/ Causa de guerra justa/ Muerte y destrucción/ Horrores/ Desastres/ Devasta- ciones


-CORTÉS EN MÉJICO

-CONQUISTADORES-
3-6-7-8-17-62-63-67

Crueldad/ Ferocidad/ Ladrones/ Asesinos/ Sin virtud/ Sin honor

Aventureros/ Sin escrúpulos/

Sangre del indio/

Acuchillamiento/ Degüello/

Exterminio de la población

\section{-METALES PRECIOSOS-}

-TRABAJOS DE AZTECAS

EN CAMPOS Y MINAS

- TRABAJOS EN UNA MINA

AURÍFERA

Corona

Oro y Plata como Principal

Objetivo/ Ambición de la

-LAS CASAS- 11-14-71

Causa del indio/ Atrocidades

dominación española/ Voz no

escuchada/ Esclavitud/

Derecho del indio a la

dignidad humana

\section{-IMPERIOS INDIOS-}

-SIETE DIBUJOS ANÓNIMOS

DE LA ÉPOCA DE LA

9-40-11-14-71-10-55

CONQUISTA AZTECA

Destrucción/Jactancia/

Esclavitud/ Trabajo abusivo

\section{-CRISTIANIZACIÓN-}

-CANIBALISMO DE LOS

INDÍGENAS

\section{5-47}

Bautismo bajo amenaza/

Prisión/

Tortura/Muerte/Idolatría

-PAPADO-

Su utilización económicapolítica por la Corona 
-FELIPE II- 18-22

Colonización europea de su Imperio/ Represión religiosa y herética/ Guerra Santa/ Persecuciones/ Inquisición/ Dispersión de moriscos y conversos/ Autos de Fe/ Desprecio por actividad productiva/ Única Confianza económica en la explotación de las colonias/ España era una colonia en sí misma

- SANTO OFICIO/ INQUISICIÓN -

-EJECUCIONES PÚBLICAS DE BRUJAS Y HEREJES -QUEMA DE HEREJES

\section{3-24-26-45}

Utilización por los monarcas/ Persecución de la homosexualidad, bigamia y fornicación/

Expulsiones en masa de judíos y moriscos/ Uso del hierro y el fuego/ Rey preside Autos de $\mathrm{Fe} /$ Sede en Palacio Real de Madrid

\section{-ANTISEMITISMO- $\quad$ 25-27-28-46-47}

-QUEMA DE JUDÍOS EN LA HOGUERA

Desprecio y sospechas hacia judíos y moriscos/ Odio y envidia/ Caza del judío(S.XV)/ Imposición abandono lengua y costumbres/Acusación de quinta columna turca

-PAÍSES BAJOS-EJECUCIONES EN MASA

30-31

Levantamientos populares/ Hambre/ Anticalvinismo/ Saqueo/ Masacre/ Duque de Alba/ Motivos de roce 
-ESCLAVOS NEGROS -ESCLAVISMO-

49-50-51-52-53-54

COMO CORTADORES

DE CAÑA DE AZÚCAR

Borbones. Asiento de Negros/

-MARCA DE ESCLAVOS

Portugal y España/ Trabajos

duros e inhumanos/Cacerías

africanas/ Naves negreras

$\begin{array}{ll}\text {-CARLOS V - } & \mathbf{3 3} \\ & \text { Frío y calculador/ Imperio sin } \\ \text { porvenir/ Imperio sin unidad/ } \\ \text { Saco de Roma }\end{array}$

-SACO DE ROMA- $\quad 34-35-81$

Españoles como responsables/ 4.000 muertos/ Humillaciones/ Torturas/ Saqueo y Botín

-ITALIA-

37-38-39-42

Rapiña económica/

Explotación abusiva/

Fiscalismo/ Opresión política

< R. CULT. >

-LA RUTA DE LA INDIA Y EL DESCUBRIMIENTO DE AMÉRICA

-CONQUISTA Y COLONIZACIÓN DE AMÉRICA

-LOS INDÍGENAS EN EL MUNDO COLONIAL

-RELACIONES COMERCIALES ENTRE AMÉRICA Y ESPAÑA

-EXPLOTACIÓN DE ORO Y PLATA

-EL COMERCIO ENTRE AMÉRICA, ESPAÑA Y EUROPA

-LA CRISIS Y RECUPERACIÓN ECONÓMICA DEL SIGLO XVII

-LOS REYES CATÓLICOS 
-LAS MONARQUÍAS AUTORITARIAS

-EL IMPERIO DE LOS HABSBURGO

-EL RENACIMIENTO Y BARROCO COMO IDEOLOGÍA, CULTURA Y ARTE

\section{-ORTODOXIA Y CONTRARREFORMA}

\section{Bibliografía general:}

- Nixon, R.B.Investigaciones sobre comunicación colectiva. CIESPAL, Quito, 1965

- Kuentz,P. "Lo retórico o la puesta al margen”, en Investigaciones Retóricas II.Tiempos Contemporáneos, Buenos Aires, 1974

- Aranguren,J.L.La comunicación humana.Guadarrama, Madrid,1975

- Barbalato,B.Perspectivas sociológicas, en E.Tarroni y otros: La comunicación de masas: perspectivas y métodos.Gustavo Gili. Barcelona. 1978

- Sanvisens,A. "Persuasión y razonamiento lógico". INP,Madrid,1971

- Van Dijk. Texto y Contexto.Cátedra, Madrid,1980

- Vázquez Montalbán,M. Historia y Comunicación Social. Alianza Editorial, Madrid, 1985

- Reig, Ramón. La irrupción,1987

- Moles,A.Sociodinamica della cultura. Guaraldi, Bolonia 1971

- Reig, Ramón. Sobre la comunicación como dominio. Ed. Fundamentos, Madrid,1992.

- UNESCO. Sobre el futuro de la educación. Hacia el año 2000, Narcea, Madrid, 1990

- García del Moral, Amalio. La Mano Florecida. Gallo de Vidrio, Sevilla, 1974 (=LMF)

- García del Moral, Amalio. el pan en la mirada. Azotea,Sevilla,1977(=PM)

- García del Moral, Amalio. Testamento en la Luz. Gallo de Vidrio, Sevilla, 1980(=TL) 


\section{ANEXO}

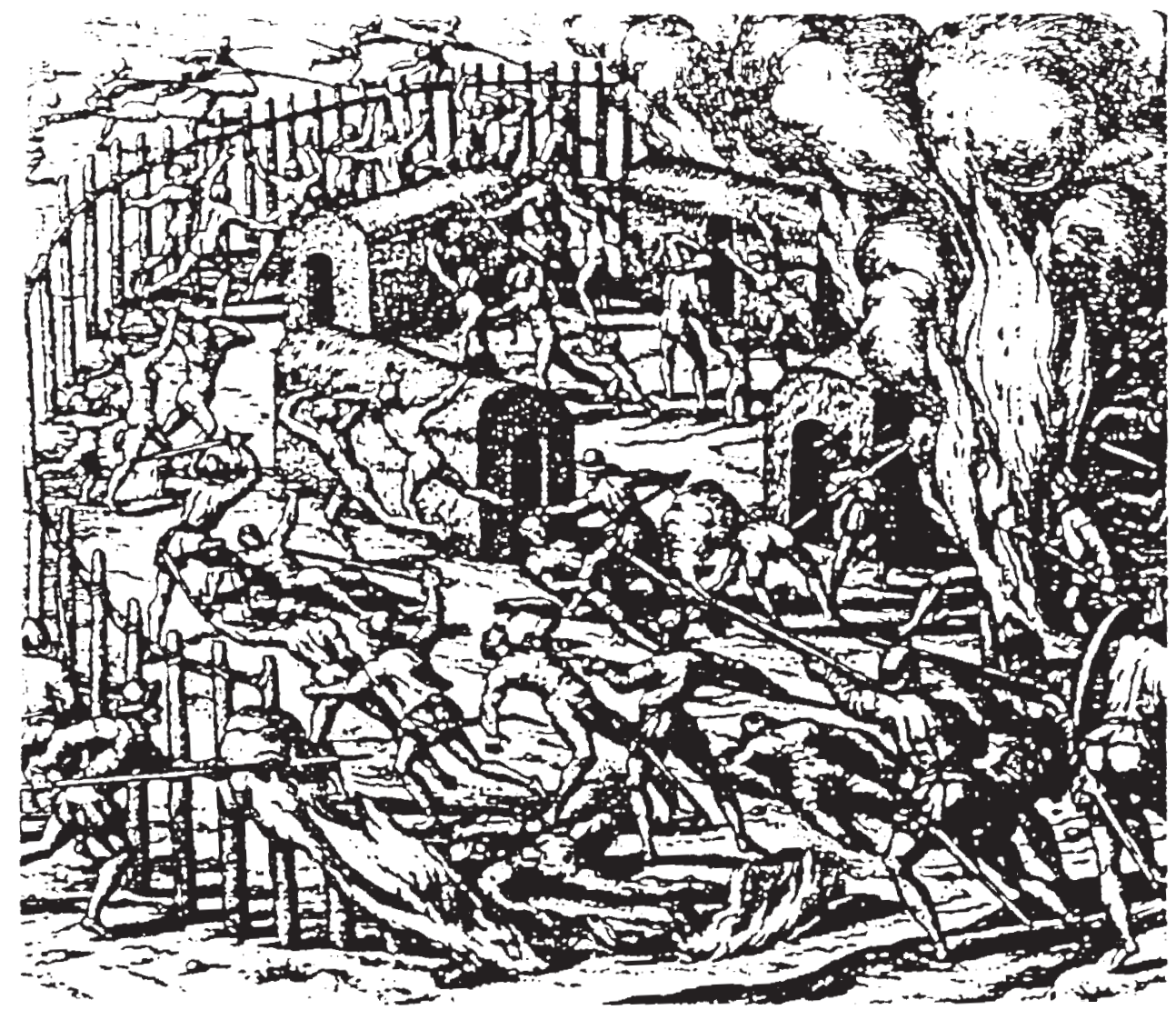

La distruzione di un villaggio indigeno ad opera degli Spagnoli. Anche dopo la conquista ci furono ribellioni, a cui i conquistatori reagirono distriggendo $i$ villaggi e massacrando gli abitanti. 

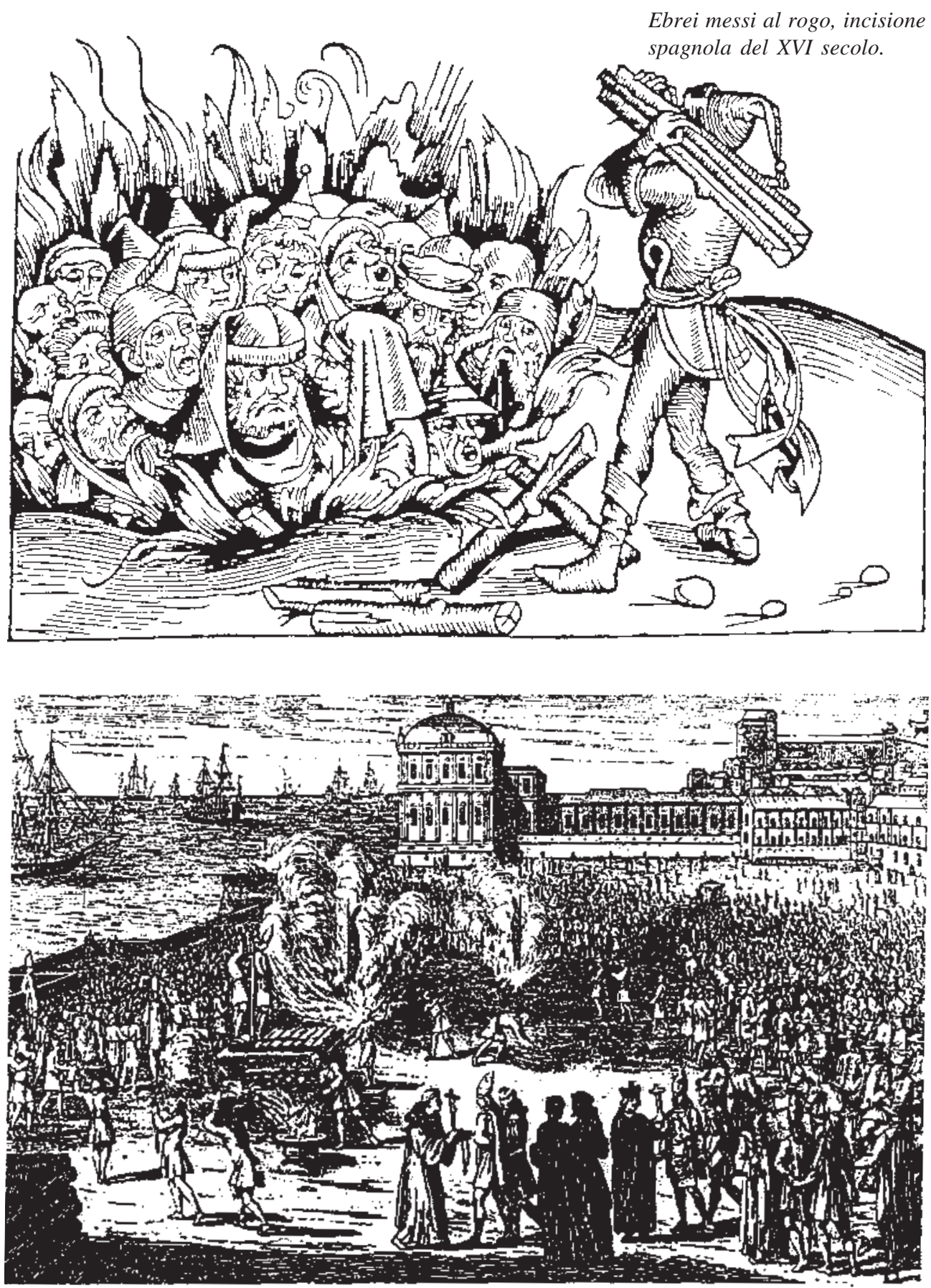

Una pubblica esecuzione di streghe e loro complici messi al rogo in Spagna, incisione del XVII secolo. 


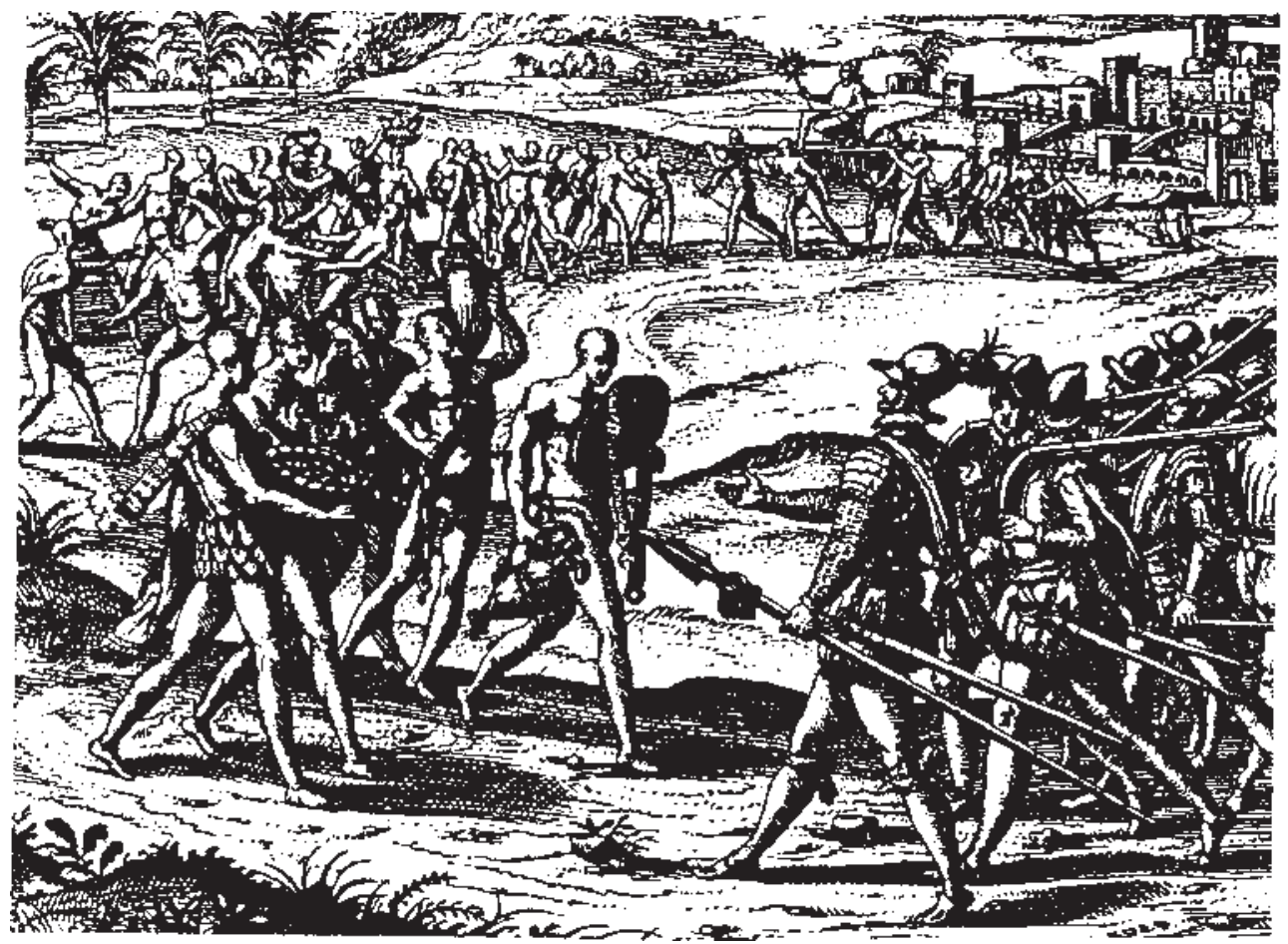

1. I primo incontro ra Cortes e Montezuma fuori della cirà di Mexico. Le accoglienze pacifiche e festose degli indigeni che, carichi di domi, reewono gli stranieri, furono seguite dal tradimento e dalle stragi dei conquistafori.

\begin{abstract}
2. Gli strumenti della superioritd spagnola: le caravelle, te armi da fuoco, le spade, covalli. Sopralturto questi witimi, sconoscinti in America centrale meridionale, atserrivano gli indigenti, git ambasciatori di Montezuma riferirono al loro imperatore che i covalli di Corter avevano wa statura kuguale all'aliezta di wha casam; gli spagnoli, dal canto loro. cercovano di sfruttare al massimo questa superioritd psicologica: Cortes fece credere agli indigeni che i cavalli parteclpavarto alle batraglite per loro volonid, animati do una collero itrefrenabile. Dove i cavalli, per lasperita del terreno, non potevano operare, emiravono in azione i coni; protelti da corozze di cuoio e addestrati a dare la caccio agli indiani, i feroci cani degh spagnoli eratro combotienti lemibilf. Alcuni di loro rimasero persino famosi nei resoconti della conquista; si ricordavano per esempio le imprese di wh cone di nome Leoncillo, dal corpo ricoperto dalle unumerose cicalrici eferite che aveva ricevuto battendosi con gli indianis.
\end{abstract}

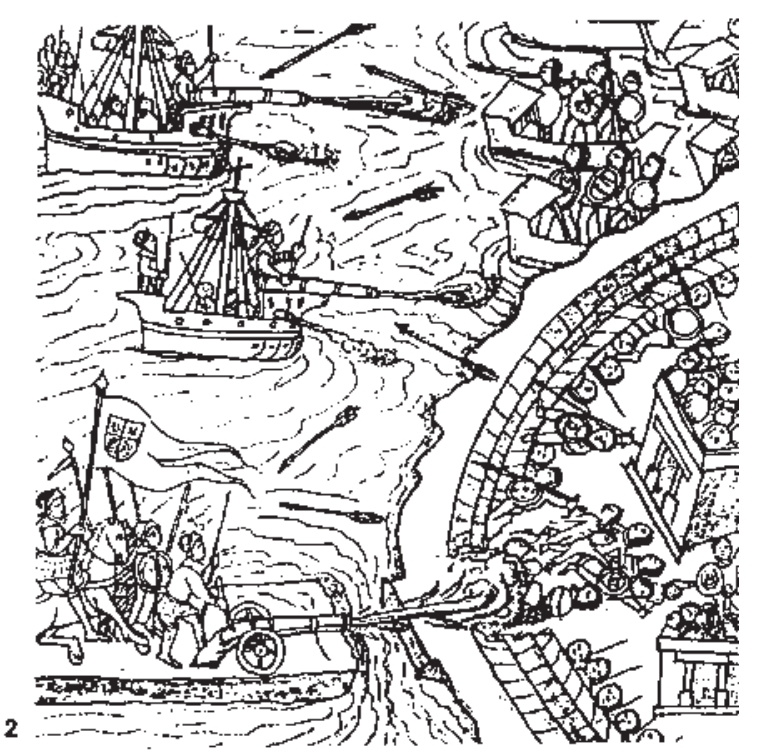




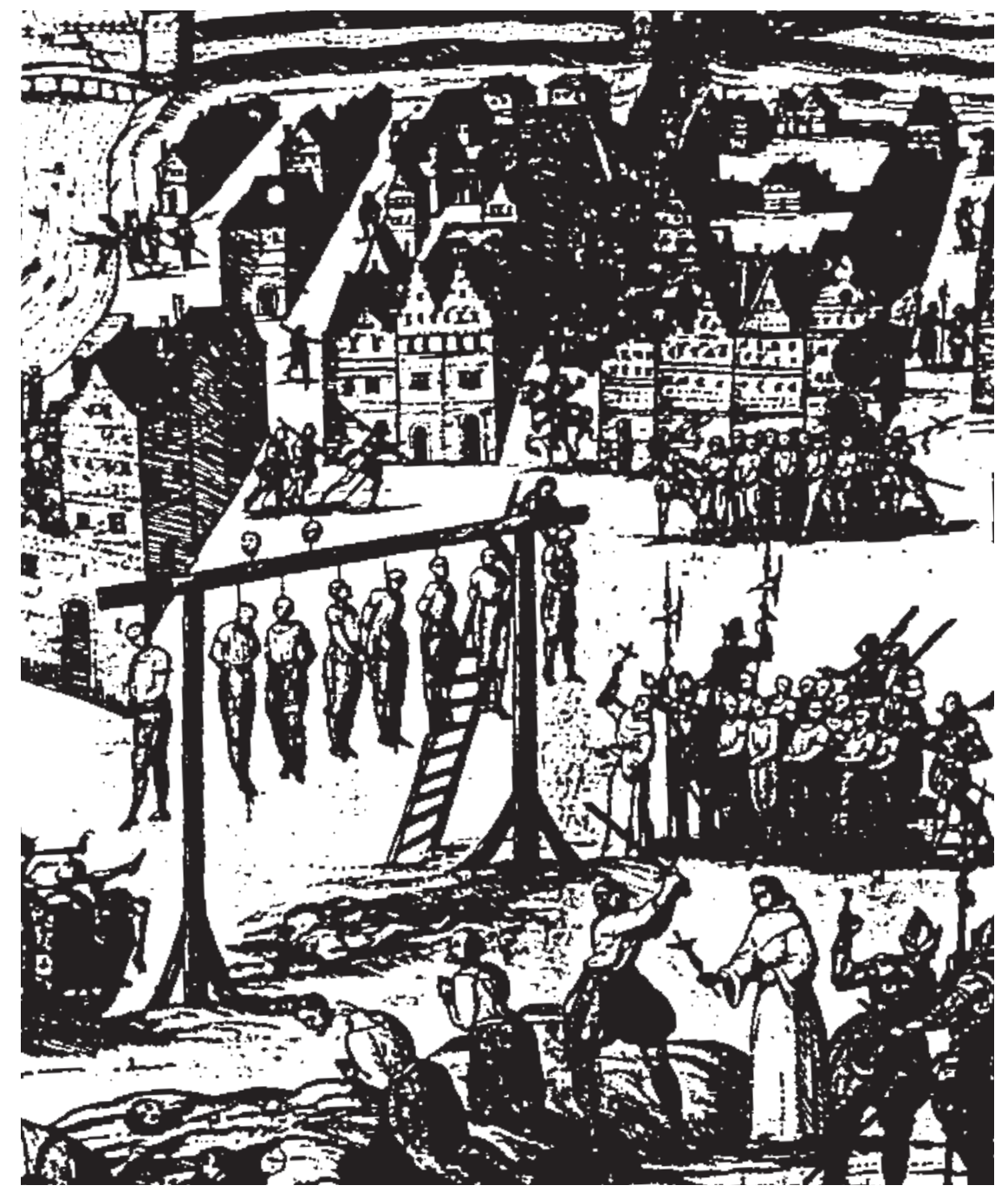

Esecuzione in massa di ribelli olandesi durante la guerra nei Paesi Bassi. La durezza della repressione spagnola fu determinante per la radicalizzazione dello scontro e spinse dalla parte dei rivoltosi anche vasti settori moderati della popolazione, che furono persi per sempre alla causa cattolica. I massacri, in questi casi, si abbatevano anche sulla popolazione inerme, sulle donne e $i$ bambini. Era infatti difficile, nelle guerre di quest'epoca, fortemente caratterizzate dal punto di vista ideologico, tenere a freno la rabbia e la cieca violenza dei soldati. Questi ultimi, inoltre, erano spesso pagati con molto ritardo, e questo acresceva la loro volontà di rapina. 